\title{
Entre becos, morros e trilhos: expansão da escola primária na cidade do Rio de Janeiro (1870-1906)
}

\author{
Between alleys, hills and rails: expansion of primary education in the \\ city of Rio de Janeiro (1870-1906) \\ Entre callejones, cerros y rieles: expansión de la escuela primaria en la \\ ciudad de Río de Janeiro (1870-1906)
}

Alessandra Frota M. de Schueler ${ }^{1}$ Irma Rizzini $^{2}$

\section{Resumo}

Estudo sobre o processo de expansão das escolas primárias no Rio de Janeiro, entre as décadas de 1870 e 1906, com ênfase nas regiões consideradas rurais ou periféricas, mais afastadas do centro da cidade, ou seja, aquelas áreas designadas como suburbanas. A abordagem abrange as possíveis convergências, e também disputas, entre ações e projetos educacionais distintos, de iniciativa do Estado e da sociedade civil, observados por meio de fontes, tais como, os requerimentos feitos à Diretoria Geral de Instrução Pública e a imprensa dos subúrbios. Respostas diferenciadas do Estado foram apresentadas às demandas por instrução, já que a municipalidade privilegiou a subvenção de escolas particulares para atender à população dos subúrbios, quando nas áreas centrais (a "cidade") predominaram as escolas públicas.

Palavras-chave: Escolas Públicas, Escolas Subvencionadas, Subúrbios.

\footnotetext{
${ }^{1}$ Doutora em Educação pela Universidade Federal Fluminense (UFF). Professora Adjunta da Universidade Federal Fluminense (UFF), Programa de Pós-Graduação em Educação. E-mail: alefrotaschueler@ gmail.com.

${ }^{2}$ Doutora em História pela Universidade Federal do Rio de Janeiro (UFRJ). Professora Associada da Universidade Federal do Rio de Janeiro, Programa de Pós-Graduação em Educação. E-mail: irma.rizzini@gmail.com.
} 


\begin{abstract}
A study about the process of the primary education expansion in Rio de Janeiro, between the 1870s and 1906, which emphasizes rural or peripheral regions, further away from the center of the city, that is, areas designated as suburban. The approach encompasses the possible convergences, as well as disputes, between distinct educational actions and projects, initiated by the state and civil society and observed through sources, such as the requests made to the General Board of Public Instruction and the suburban press. Differentiated responses from the State were presented to the demands for instruction, since the municipality favored the subsidy of private schools to serve the suburbs' population, while in central areas (nominated as the "city") the public schools predominated.
\end{abstract}

Keywords: Private Subsidized Schools, Public Schools, Suburbs.

\title{
Resumen
}

Estudio sobre el proceso de expansión de las escuelas primarias en Río de Janeiro, entre las décadas de 1870 y 1906, con énfasis en las regiones consideradas rurales o periféricas, más alejadas del centro de la ciudad, o sea, aquellas áreas designadas como suburbanas. El enfoque abarca las posibles convergencias, y también disputas, entre acciones y proyectos educativos distintos, de iniciativa del Estado y de la sociedad civil, observados por medio de fuentes, tales como, los requerimientos hechos a la Dirección General de Instrucción Pública y la prensa de los suburbios. Respuestas diferenciadas del Estado se presentaron a las demandas por instrucción, ya que la municipalidad privilegió la subvención de escuelas particulares para atender a la población de los suburbios, cuando en las áreas centrales (la "ciudad") predominaron las escuelas públicas.

Palabras-clave: Escuelas Públicas, Escuelas Subvencionadas, Suburbios. 
Certas manhãs quando desço de bonde para o centro da cidade, naquelas manhãs em que, no dizer do poeta, um arcanjo se levanta de dentro de nós; quando desço do subúrbio em que resido há quinze anos, vou vendo pelo longo caminho de mais de dez quilômetros, as escolas públicas povoadas. Em algumas delas ainda surpreendo as crianças entrando e se espalhando pelos jardins à espera do começo das aulas, em outras, porém, elas já estão abancadas e debruçadas sobre aqueles livros que meus olhos não mais folhearão, nem mesmo para seguir as lições de meus filhos.

Lima Barreto ${ }^{3}$

Afonso Henriques de Lima Barreto (1881-1922), jornalista e cronista do início do século XX, numa de suas crônicas presenteou os historiadores da educação carioca ao descrever, em algumas linhas, aquilo que, na sua perspectiva, representava o movimento de expansão das escolas públicas de primeiras letras na cidade, no percurso cotidiano entre o subúrbio e o centro. As "escolas povoadas" eram avistadas, na sua pena, por mais de dez quilômetros de distância. ${ }^{4}$

A partir da criação literária, à boa moda da crônica diária, podemos perceber os indícios de práticas de escolarização e ensino de primeiras letras, em escolas públicas, subvencionadas pelos poderes públicos e/ou particulares, que se espalhavam pelos mais variados territórios e espaços da cidade do Rio de Janeiro, compondo uma malha heterogênea e diversa, escondida entre ruas e becos tortuosos, nas ladeiras dos morros e nos caminhos mais distantes, percorridos pelos bondes, transportes urbanos e trens de ferro.

No presente trabalho, nosso objetivo consiste em investigar o processo de expansão das escolas primárias no Rio de Janeiro, entre as décadas de 1870 e 1906, privilegiando as regiões consideradas rurais ou periféricas, mais afastadas do centro da cidade, ou seja, aquelas áreas designadas como suburbanas. Entre as questões que norteiam a pesquisa, destacamos: qual a relação entre a expansão das escolas com as possibilidades de existência de uma demanda por educação e letramento, tendo em vista o crescimento, a densidade e a heterogênea composição populacional das freguesias e distritos suburbanos? Quem eram os agentes (Estado, professores, grupos sociais, imprensa, famílias), que estiveram à frente da criação ou da reivindicação pela abertura de escolas e instituições educacionais nas regiões em que residiam?

Neste sentido, a ênfase na expansão da escolarização pelas freguesias/distritos do município não descuida da intenção de enfocar as possíveis convergências, e também disputas, entre ações e projetos educacionais distintos, ancorada na tentativa de buscar ações individuais, localizadas, com a perspectiva de que os indivíduos possuem relativa margem de liberdade em relação às normas sociais. Suas escolhas dependem da experiência e da convivência com determinados grupos e valores e dos tipos de relacionamento que estabelecem. Assim, o historiador não está apenas atento para a interpretação dos significados possíveis, mas para a definição das ambiguidades do mundo simbólico, a pluralidade das interpretações desse mundo e as lutas que ocorrem em torno de recursos simbólicos e materiais (REVEL, 1998).

\footnotetext{
${ }^{3}$ Tenho esperança que...Bagatelas, 3 de maio de 1918. In: BARRETO, Lima. Crônicas escolhidas. São Paulo, Ática, 1995, p. 13.

${ }^{4}$ Lima Barreto nasceu no subúrbio da cidade do Rio de Janeiro, onde residiu por toda a sua vida. Era neto de escrava e filho de pais mulatos. Sua mãe, D. Amélia Augusta Pereira de Carvalho, era filha de escrava e agregada da família Pereira Carvalho, recebeu educação e foi professora primária no subúrbio de Todos os Santos. Seu pai, João Henriques Lima Barreto, foi tipógrafo e almoxarife na Colônia de Alienados. Após cursar a escola primária e frequentar cursos de preparatórios, Lima Barreto ingressou na Escola Politécnica com a pretensão de formar-se em Engenharia, mas não chegou a concluir o curso. Como seu pai, o jornalista e escritor exerceu a função de amanuense, funcionário público na Secretária de Guerra. (SILVA, 2005, p. 178)
} 


\section{Demandas por escolas nos subúrbios: professores e moradores}

De acordo com o Censo de 1872, havia no município neutro 19 paróquias ou freguesias, sendo 11 urbanas, com um total de 220.000 habitantes (Engenho Velho, São Cristovão, Espírito Santo, Santana, Santo Antonio, Sacramento, Candelária, São José, Santa Rita, Glória, Lagoa), e 8 rurais, com cerca de 50.000 habitantes (Santa Cruz, Guaratiba, Campo Grande, Jacarepaguá, Irajá, Inhaúma, incluindo-se as Ilhas do Governador e de Paquetá).

Uma grande parte da população do Rio de Janeiro concentrava-se nas áreas consideradas urbanas. Nestas áreas também era mais expressivo o número de escolas públicas primárias. Em números absolutos, o município, em 1876, contava 95 escolas públicas, 49 de meninos e 46 de meninas. As "freguesias de dentro" ou urbanas possuíam 68 estabelecimentos, contando com o recém-inaugurado Asilo dos Meninos Desvalidos, em Vila Isabel. Os novos edifícios escolares, ironicamente denominados pelos críticos de palácios, construídos nos anos 1870 e 1880 (total de 7 prédios), via de regra, foram erguidos nestas localidades, com destaque para as praças públicas. Nas freguesias "de fora", rurais ou suburbanas, havia 27 escolas públicas, segundo dados de $1876 .{ }^{5}$ (MARTINEZ, 1997)

Nesse contexto, os principais núcleos suburbanos cariocas estavam em franca expansão. Como lembra Benchimol (1992), Queimados, Maxambomba (atual Nova Iguaçu), Cascadura, Engenho Novo, São Cristóvão, Sapopemba (atual Deodoro), São Francisco Xavier, Riachuelo e Todos os Santos foram as primeiras estações da estrada de ferro da Central do Brasil, inauguradas entre 1858 e 1870. Nos anos de 1880 foram abertas as estações de Engenho de Dentro, Piedade, Rocha, Derby Club, Sampaio, Quintino, Méier, Mangueira, Encantado e, em 1890, a de Madureira. Os subúrbios de Inhaúma e Irajá eram servidos pela Estrada de Ferro Rio D’Ouro, construída na década de 1880. A Rio de Janeiro Northern Railway Company, conhecida posteriormente como Leopoldina, inaugurada em 1886, ligou São Francisco Xavier a São João de Meriti (atual Duque de Caxias), cujo eixo deu origem às estações de Bonsucesso, Ramos, Olaria, Penha, Brás de Pina, Cordovil, Parada de Lucas e Vigário Geral.

A extensão das linhas de trem e de outros meios de transporte público promovia a circulação cotidiana de pessoas, trabalhadores e mercadorias, processo que apontava para a relação indissociável entre as áreas urbanas e suburbanas, tornando contínuos, fluidos e móveis as fronteiras da cidade. Em Feiras e Mafuás, crônica publicada na Gazeta de Notícias, em 28 de julho de 1921, Lima Barreto chamou atenção para a indissociabilidade entre trilhos e ocupação dos subúrbios do Rio de Janeiro: "Na vida do subúrbio a estação da estrada de ferro representa grande papel, é o centro, é o eixo desta vida. (...) De resto, é em torno da estação que se aglomeram as principais casas de comércio do respectivo subúrbio" (BARRETO, 1921, p. 2).

Entre trilhos, morros e becos, as escolas primárias também seguiam o crescimento urbano, como notou, já em 1919, o próprio escritor na crônica que serve de epígrafe a este texto. Em Clara dos Anjos, romance publicado em folhetim no início da década de 1920, o narrador observava: "o subúrbio propriamente dito é uma longa faixa de terra que se alonga, desde o Rocha ou São Francisco Xavier, até Sapopemba, tendo para eixo a linha férrea da Central” (BARRETO, 1922, p. 38). ${ }^{6}$

\footnotetext{
5 Mapa das Escolas - Anexos do Relatório do Ministro do Império (BRAZIL, 1877). Disponível em: http://brazil.crl.edu/bsd/bsd/u1742/000001.html. Acesso em: 10/03/2017.

${ }^{6}$ Último romance escrito por Lima Barreto, Clara dos Anjos foi publicado parcialmente, em 1921, na revista carioca $O$ Mundo Literário. A primeira edição em livro data de 1948. Este livro é representativo de grande parte das preocupações que rondaram a obra do autor, incluindo crônicas e romances. Lá estão o subúrbio carioca, as questões raciais, as diferenças de classe e a modernização do Rio de Janeiro no início do século XX. Clara dos Anjos é uma mulata pobre do subúrbio, filha do carteiro João dos Anjos e de Dona Engrácia. Por meio de amigos do pai, Clara conhece Cassi Jones, malandro de família mais abastada e notório galanteador. A despeito dos alertas de seu padrinho - que será brutalmente assassinado -, Clara inicia uma relação com Cassi. A partir desse encontro fadado à tragédia, Lima coloca o leitor dentro de um jogo de tensões raciais e de classe, sedução e preconceito social. Ao mesmo tempo, traça rica e minuciosa representação sobre o cotidiano nos subúrbios do Rio, com suas alegrais, tristezas e mazelas. Sobre o contexto social e histórico de emergência da obra, consultar Nicolau Sevcenko (2003).
} 
Para concretizar os projetos de escolarização, o governo imperial, e posteriormente, o regime republicano, preconizava aliar a sua ação à da iniciativa da sociedade civil, subvencionando instituições particulares, incentivando as associações de instrução e conclamando os professores e a população para prestar serviços gratuitos e donativos em nome da instrução popular. O Estado procurava dirigir e controlar o ensino público, ao mesmo tempo em que concedia a liberdade para os proprietários de colégios ou filantropos a agirem em prol da instrução. O público e o privado, longe de constituírem instâncias separadas e antagônicas, mesclavam-se e confundiam-se, ora promovendo projetos comuns e alianças, ora disputando por monopólios e interesses distintos, num processo dinâmico, onde estavam em jogo tanto bens materiais quanto valores simbólicos e culturais (PASCHE, 2014).

Apenas para oferecer um exemplo das imbricações entre os poderes públicos e particulares na criação, e na manutenção de escolas primárias, vale a pena recuperar brevemente a história da escola regida por D. Maria Brazil Silvado, aberta em 1877, por sua iniciativa. Em seu ofício às autoridades, escrito no ano de 1890, ela fez um pequeno histórico de suas atividades docentes no bairro do Rio Comprido, na Rua Malvino Reis, número 74, onde atendia a 24 "meninas de famílias pobres". A partir de março de 1877, segundo a professora, com a subvenção do governo imperial, a escola aumentou a matrícula, passando a contar com uma média anual de frequência de 48 meninas. Dentre estas alunas, havia, em 1890, apenas 15 contribuintes, sendo o restante, composto por meninas pobres que frequentavam a escola "gratuitamente", ou melhor, subsidiadas pelos cofres do Estado. ${ }^{7}$

A cidade se expandia e as escolas emergiam nas localidades mais distintas, por iniciativa de sujeitos sociais diversos. ${ }^{8}$ Nos anos de 1870 a 1900, o movimento de correspondências entre as autoridades da administração pública e os professores particulares da cidade revela o crescimento significativo das escolas públicas e das subvenções às casas de escolas nas regiões mais afastadas do centro urbano, especialmente nos subúrbios da Central do Brasil e nas regiões consideradas rurais, como Campo Grande, Santa Cruz e Guaratiba ${ }^{9}$ (LIMEIRA, 2008). No decorrer de todo o período privilegiado na pesquisa, professores, pais de família e moradores das áreas suburbanas e freguesias rurais aparecem na documentação preservada pelo Fundo de Instrução Pública do Arquivo Geral da Cidade do Rio de Janeiro como sujeitos ativos no processo de escolarização nas suas regiões.

Em Jacarepaguá, o professor primário Philippe de Barros e Vasconcellos, por exemplo, se preocupou em enumerar a lista de crianças pobres atendidas por sua escola, para as autoridades do Ministério do Império. Chamava atenção dos poderes públicos para a falta de recursos das famílias para manter seus filhos estudando, apontando o trabalho nas casas e nas roças como um dos maiores empecilhos à regularidade da presença de seus alunos nas aulas cotidianas. ${ }^{10} \mathrm{Na}$ Freguesia de Campo Grande, a professora Anna Alexandrina Vasconcellos Medina relatou ao Inspetor Geral que sua escola, contando 34 meninas, começou a funcionar em 21 de janeiro de 1871 com poucos bancos e móveis, emprestados pelo negociante e morador, José da Costa Pereira, a cujos esforços ela devia a permanência de sua atividade docente. ${ }^{11}$

$\mathrm{Na}$ Freguesia de Inhaúma, o delegado responsável pela físcalização das escolas primárias, ao elaborar uma lista de crianças pobres que não frequentavam a escola pública por falta de vestuário adequado, afirmava que a procura pelas vagas havia aumentado em razão das atividades do censo de 1872, nas quais os pais de família eram inquiridos sobre a instrução dos

\footnotetext{
${ }^{7}$ AGCRJ, 12.1.8. Ofício da professora Maria Brazil Silvado, s/d (1890), fl. 264.

${ }^{8} \mathrm{Em} 1872$, a população suburbana representava $17 \%$ do total dos habitantes registrados no Rio de Janeiro. O percentual subiu para $23 \%$ em 1906, como resultado da expansão demográfica, comercial e industrial e também dos transportes, que ligavam o centro às regiões periféricas da cidade. Dados em Silva, 1988, p. 90.

${ }^{9}$ AGCRJ, 12.1.15. Escolas Subvencionadas - 1894-1900.

${ }^{10}$ AGCRJ, 10.4.19. Ofício do professor Philippe de Barros e Vasconcellos, 12/09/1872, fl. 28.

${ }^{11}$ AGCRJ, 11.3.28 Ofício da professora Anna Alexandrina de Vasconcellos Medina, 28/01/1871, fl. 45.
} 
filhos ou dos menores sob sua responsabilidade. ${ }^{12}$ Como ocorreu em toda a área suburbana, Inhaúma abrigava contingente expressivo de empregados domésticos, operários, trabalhadores em ofícios manuais, comerciantes e funcionários públicos. A região experimentou significativo crescimento demográfico e comercial nas décadas finais do século XIX e no primeiro decênio do século seguinte, impulsionado pela expansão das linhas férreas e dos transportes públicos e pelas sucessivas reformas urbanas ocorridas nas áreas centrais do Rio de Janeiro ${ }^{13}$.

Assim, não foi mero acaso a emergência da imprensa periódica como porta-voz importante das reivindicações e demandas da população residente em Inhaúma. Letrados, comerciantes, bacharéis, professores, médicos, jornalistas e outras lideranças locais envolveram-se na publicação de periódicos, que entre outras questões, privilegiaram o debate sobre as condições de vida e os problemas enfrentados pelos moradores dos subúrbios. Serviços públicos, como água, saneamento, iluminação, transporte, obras e calçamento de ruas, educação e saúde foram temáticas constantes nos editoriais, artigos, informes e notas públicas na chamada imprensa dos subúrbios (MENDONÇA, 2008; MYSAYAKA, 2011). O Echo Suburbano, que iniciou suas edições em 03 de janeiro de 1901, numa tipografia da Rua Dr. Manoel Vitorino, n. 12, em Inhaúma, representa uma das folhas que trouxeram, entre outras reivindicações, as demandas por educação e escolas, além de publicar anúncios, informes e notícias de professores, escolas e colégios da localidade. Em 1901, por exemplo, anunciava as atividades do Colégio de São Thiago de Inhaúma, dirigido pelo professor Antonio Manoel Pereira dos Santos, na Estrada Velha da Pavuna, que oferecia ensino primário gratuito para jovens e adultos (MYSAYAKA, 2011). Anunciou ainda a existência de 9 professores e 8 colégios na região, entre eles o Liceu Popular de Inhaúma, que funcionava na sede das Oficinas da Estrada de Ferro Central do Brasil, desde maio de 1902, sob a direção do professor Maia Maciel, também editor e colaborador em outro periódico local, o Progresso Suburbano (MYSAYAKA, 2011). A educação feminina também crescia, havendo na localidade notícias de 17 escolas femininas, a cargo de professoras particulares, mas subvencionadas pelo poder público municipal. Fechamento, transferências de escolas e outras reclamações por má conduta de professores também compareciam como temáticas nas folhas locais. ${ }^{14}$

O Progresso Suburbano, por sua vez, dedicou-se no ano de 1902, em sua coluna "Instrucção Publica", a denunciar o fechamento, a transferência e a falta de materiais e móveis nas escolas de Piedade, sede do jornal, e em outros locais, como Madureira e Penha, ocorrências que favoreciam a "vadiação" dos meninos. Na contramão das denúncias que revelavam a vulnerabilidade das escolas da região, surgiam notícias que indiciavam o envolvimento de grupos locais com a instrução popular, como a escola mantida pela Irmandade da Penha no local aonde funcionava de forma precária a escola subvencionada ${ }^{15}$.

Outro jornal muito atuante na temática da educação do povo é O Suburbano, Orgam dos interesses locais, fundado na Ilha do Governador, em 1900, por Antonio Hilário da Rocha. No ano de 1900, seus redatores foram incansáveis nos apelos ao poder público e aos pais de família: no primeiro caso, para a subvenção de escola na praia de Flecheiras, onde funcionava a escola do professor Arthur Pereira, sem apoio da prefeitura; no segundo, em colunas como a "Instrucção publica" e "Pela instrucção", tentava sensibilizar os pais para que enviassem os filhos às escolas, já que eram em número suficiente e providas de pessoal idôneo. Dos 5 mil habitantes, estimava-se a existência de 500 crianças em idade escolar, porém somente 248

\footnotetext{
${ }^{12}$ AGCRJ, 10.4.19. Ofício do delegado de Instrução de Inhaúma, 01/10/1872, fl. 82.

${ }^{13}$ Em Inháuma, o Censo de 1890 registrou o percentual de $36 \%$ da população alfabetizada e $64 \%$ analfabetos. Para o ano de 1906, 48\% dos moradores foram registrados como alfabetizados (MYSAYAKA, 2011).

${ }^{14}$ Sobre má conduta de professores e transferência de escolas, ver notícias publicadas na Gazeta de Notícias, em 13 de janeiro de 1888, casos referentes à Campo Grande (p. 1, colunas 3 e 4).

${ }^{15}$ PROGRESSO SUBURBANO. Instrucção Publica, 6/08/1902, edição 11, p. 3.
} 
estavam matriculadas nas escolas públicas existentes. ${ }^{16}$ Consta que "Na vizinhança de alguns estabelecimentos vê-se quase sempre muitas crianças vagando durante as horas escolares, não tendo portanto os paes desculpa alguma a dar relativamente ao abandono em que deixam seus filhos". Garante que pais muito pobres mandam os filhos às escolas com suas "roupinhas modestas" enquanto que pais mais protegidos pela sorte mantêm seus filhos em casa, muitas vezes em completa ociosidade. ${ }^{17}$

A imprensa suburbana vinha desde o século XIX dedicando-se ao tema da instrução popular, de iniciativa oficial e de outros grupos. Um destes jornais é a Gazeta Suburbana, de Todos os Santos, Piedade, focada nos problemas vividos pela população suburbana, mas sem deixar de acompanhar as questões pertinentes à instrução na Corte. Em "Cartas a minha prima", o assinado "A. Roza" acompanhou as notícias sobre a criação de escolas na Corte, elogiando a educação de um povo "saturado de civilisação africana" (grifo no original), porém questionou a construção de palácios escolares para os filhos dos pobres, a quem seria sacrifício comprar sapatos e vestuário. Não esquecendo as regiões mais distantes, apontava a dificuldade da frequência às aulas nas freguesias extensas. ${ }^{18}$

Na década de 1880, o delegado das escolas municipais suburbanas, Bento Barroso Pereira, apresentou ao governo uma listagem com o número de estabelecimentos, matrículas, "frequência máxima e mínima" (dados referentes ao mês de agosto de 1882), documento que nos permite perceber a demanda pela escolarização nas freguesias mais interioranas de Guaratiba, Curato Santa Cruz, Campo Grande. Em Guaratiba, alegou ter encontrado 100 alunos matriculados, sendo 50 meninos e 48 meninas (sic), com frequência máxima de 73 crianças e frequência mínima de 23. Em Santa Cruz, registrou a matrícula de 56 alunos, 41 meninas e15 meninos, com frequência máxima de 40 e mínima de 22. Já na freguesia de Campo Grande, havia 30 matrículas, 19 de meninas e 11 de meninos, com frequência máxima de 22 crianças e mínima de $12 .{ }^{19}$ Em 15 de dezembro de 1882, o diretor das escolas suburbanas produziu o relatório circunstanciado sobre as atividades escolares nas escolas primárias mistas municipais, retomando a história de sua criação. Segundo ele, a Câmara Municipal, preocupada com a necessidade de desenvolver a instrução primária, instituiu, por medida aprovada em 20 de maio de 1881, as escolas mistas de Santa Cruz, Guaratiba e Campo Grande, visando a facilitar o acesso das crianças de ambos os sexos às escolas públicas, iniciativa que teria sido muito "aplaudida pela população suburbana". As escolas mistas funcionariam nas casas alugadas para esse fim e teriam sido providas de professoras efetivas e adjuntas e equipadas com os utensílios necessários ao ensino. ${ }^{20}$

Iniciativas particulares de movimentos sociais, como o republicano e o abolicionista, eram noticiadas na imprensa carioca. Em São Cristóvão, desde pelo menos 1874, o Club Republicano, sob a direção de Emiliano Rosa de Senna, abriu um curso noturno para o ensino de livres e escravos, o qual contou com a participação de José do Patrocínio, abolicionista e jornalista, que viria a ser membro de sua família, ao casar com uma de suas filhas (SCHUELER, 2016). A iniciativa obteve sucesso e permaneceu sob a liderança dos republicanos de São Cristóvão, como informava o jornal $O$ Espinho, em 19 de novembro de $1882 .{ }^{21}$ Além da escola noturna, o Club Republicano associava-se à Sociedade Amante da Instrução para a abertura de cursos e promovia a compra de alforrias no bairro. O jornal também destacava a existência de outras escolas públicas e colégios privados, incluindo o Liceu de São Cristóvão, iniciativa

\footnotetext{
${ }^{16}$ O SUBURBANO, 15/06/1900, Edição 8, p. 2.

17 O SUBURBANO, 15/07/1900, Edição 10, p. 3.

${ }^{18}$ GAZETA SUBURBANA. Cartas a minha prima, 30/08/1884, Edição 21, p. 2 e 3.

${ }^{19}$ AGCRJ, 11.4.23. Ofício do delegado das freguesias suburbanas, Bento Barroso Pereira, de 01/09/1882, fl.81.

${ }^{20}$ AGCRJ, 11.4.23. Ofício do delegado das freguesias suburbanas, de 15 de dezembro de 1882, fls. 84 a 91.

${ }^{21}$ O ESPINHO, 19/11/1882, Edicão 2, p. 1 e 2.
} 
particular de instrução secundária, dirigido pelo cidadão Souza Dias. ${ }^{22}$ Iniciativas voltadas exclusivamente para a promoção da instrução eram celebradas nas páginas dos jornais. A Associação Propagadora da Instrução Popular do Engenho Novo, criada com a participação de "grande número de moradores dos subúrbios", montou escola com programa de ensino ampliado, que incluía leitura, gramática portuguesa, francês, contabilidade, desenho, caligrafia e música, oferecendo ensino grátis aos 38 alunos matriculados em novembro de 1883. O jornal elogiava o "grande aproveitamento" dos alunos, sob os cuidados de oito professores dedicados às matérias. ${ }^{23}$

O "progresso" e a "civilização" dos subúrbios cariocas eram temáticas recorrentes nos jornais editados por moradores, comerciantes e políticos locais. Realçando o crescimento do comércio, dos transportes, das sociedades dramáticas e companhias de teatro, da dança e da música, das escolas e outras instituições culturais e educativas, a Gazeta Suburbana publicou uma matéria sobre "O que é a verdade" nas áreas afastadas do centro: São Cristóvão, Engenho Novo, Todos os Santos, Engenho de Dentro, todas estas localidades, compareciam como locais de desenvolvimento cultural e social. ${ }^{24} \mathrm{Na}$ Piedade, em Todos os Santos, por exemplo, local onde residiu Lima Barreto, o jornal elogiava a iniciativa da Sociedade Musical Progresso do Engenho de Dentro ${ }^{25}$, responsável pela abertura de um curso noturno gratuito para crianças e adultos. Neste, além da música e da dança, que iniciavam os alunos no ofício de músico, ensinava-se as primeiras letras. Diante das novidades, entre as quais figurava o próprio periódico como prova dos "ares de civilização", o jornalista concluía:

Ora, o que é tudo isto que acabamos de expor, e mais alguma cousa, como sejam: escolas bem dirigidas, pharmácias bem montadas, armazéns em grande escala, hotéis, etc., senão a prova mais cabal do progresso suburbano? Como negá-lo pois? ${ }^{26}$

\section{Expansão (desigual) da escolarização nos subúrbios: a subvenção ao ensino particular}

A imprensa carioca, com suas colunas sobre os subúrbios e seus jornais criados pelos moradores dos bairros suburbanos, atentava para o rápido crescimento da região, incluindo o demográfico. De fato, o aumento populacional nos subúrbios, entre 1890 e 1906, foi estimado na ordem de $100 \%{ }^{27}$. Já as áreas do centro e sul, e parte do norte do município, obtiveram um crescimento bem menor, segundo dados divulgados pela prefeitura em 1907: 46\%. A tabela I apresenta os dados populacionais de acordo com a divisão territorial empregada nos censos.

\footnotetext{
${ }^{22}$ O ESPINHO, 10/12/1882, Edição 5, p. 1.

${ }^{23}$ GAZETA SUBURBANA, 2/02/1884, Edição 5, p. 2.

${ }^{24}$ Propagandas de instituições particulares podem ser encontradas nos jornais. Na Gazeta Suburbana, de 26/07/1884, anunciavam-se colégios de meninas em Maria da Graça e de meninos em Todos os Santos. Edição 18, p. 4.

${ }^{25}$ Em outra matéria do mesmo jornal, o articulista criticou a iniciativa da Estrada de Ferro, nas Oficinas de Engenho de Dentro, que teria aberto um curso noturno somente para atender aos filhos dos operários. Em contrapartida registrou novos elogios à Sociedade Musical. Destacou que os cursos desta sociedade foram abertos para quaisquer interessados, o que decorria do "seu desejo de elevar o nível intelectual do povo: o mais é pomada para inglês ver” (sic). GAZETA SUBURBANA, 30/11/1884, Edição 28, p. 2.

${ }^{26}$ GAZETA SUBURBANA. O que é verdade, 15/12/1883. Edição 1, p. 1 e 2.

${ }^{27}$ Entre 1890 e 1906, a população total do Distrito Federal aumentou na ordem de 55,26\%, passando de 522.651 para 811.443 habitantes (Tabela I). Os dados do censo de 1890, citados neste artigo, foram consultados na publicação de 1907, da prefeitura do Rio de Janeiro, sobre o recenseamento realizado no município entre 1906 e 1907 , determinado pelo prefeito Pereira Passos em 1905, mas somente iniciado ao final de sua gestão. A obra apresenta um forte caráter memorialístico, recorrendo a textos e fotografias sobre a cidade (edificações, avenidas, praças, parques e belas paisagens). O livro recebeu nova edição em ....* pelo Instituto Pereira Passos e encontra-se disponível em: https://ia601403.us.archive.org/29/items/recenseamentodo01bragoog /recenseamentodo01 bragoog.pdf.
} 
Tabela I - Número de habitantes das diversas circunscrições civis nos anos de 1890 e 1906

\begin{tabular}{|c|c|c|c|c|c|c|}
\hline \multirow[b]{2}{*}{ Freguesias } & \multicolumn{4}{|c|}{ População } & \multicolumn{2}{|c|}{ Diferença no período } \\
\hline & $\begin{array}{c}\mathrm{Em} \\
1890 \\
\end{array}$ & $\%$ & $\begin{array}{c}\text { Em } \\
1906\end{array}$ & $\%$ & Absoluta & $\%$ \\
\hline Cidade & 425.386 & 81,39 & 619.648 & $\overline{76,36}$ & 194.262 & 45,67 \\
\hline Subúrbios & 92.906 & 17,78 & 185.687 & 22,88 & 92.781 & 99,87 \\
\hline $\begin{array}{l}\text { População } \\
\text { terrestre }\end{array}$ & 518.292 & & 805.335 & & 287.043 & 55,38 \\
\hline $\begin{array}{l}\text { População } \\
\text { marítima }\end{array}$ & 4.359 & 0,83 & 6.108 & 0,75 & 1.749 & 40,12 \\
\hline População total & 522.651 & 100 & 811.443 & 100 & 288.792 & 55,26 \\
\hline
\end{tabular}

Fonte: Adaptado de Marques, 2013, p. 43, e Recenseamento, 1907, p. 23.

Em 1892, a expansão urbana se refletiu na organização político-administrativa da cidade. Na Lei Orgânica do Distrito Federal, a urbs foi dividida em 21 distritos, permanecendo como rurais os distritos de Inhaúma, Irajá, Jacarepaguá, Guaratiba, Campo Grande, Santa Cruz, Ilha do Governador e Ilha de Paquetá. No documento da Prefeitura Municipal, datado de 1907, essas regiões foram consideradas subúrbios (Recenseamento, 1907). Este documento, porém, aborda a artificialidade e a complexidade de tal divisão administrativa, pois, embora estes distritos tenham continuado a serem designados como áreas suburbanas em períodos posteriores, os que sofreram maior crescimento populacional, como os de Inhaúma e Irajá, passaram a receber tratamento semelhante aos distritos urbanos em termos de licença para construir e cobrança de impostos, gerando tensões entre a população e o poder municipal. ${ }^{28}$ Fatos que não passaram despercebidos na pena de Lima Barreto:

Por esse intrincado labirinto de ruas e bibocas é que vive uma grande parte da população da cidade, a cuja existência o governo fecha os olhos, embora lhe cobre atrozes impostos, empregados em obras inúteis e suntuárias noutros os pontos do Rio de Janeiro (BARRETO, 1922, p. 39).

No que se refere à organização da instrução pública municipal, o Decreto n. 38, de 09 de maio de $1893^{29}$, dividiu a cidade em 12 distritos escolares, tendo sido nomeados para a fiscalização das escolas 12 delegados, no dia 16 do mesmo mês. No Relatório da Diretoria Geral de Instrução Pública, datado de 23 de agosto de 1893, havia a indicação da existência de 143 escolas públicas de $1^{\circ}$ grau e 42 escolas particulares subvencionadas pelos cofres municipais. ${ }^{30}$ Segundo as autoridades do ensino, o custo médio das escolas subvencionadas era de 105 dólares, valor que era destinado mensalmente ao professor regente. ${ }^{31}$ No mesmo relatório, é relatado que as escolas iniciaram seus trabalhos em 01 de março e apresentaramse à matrícula 9.622 alunos, 4.525 meninos e 5.027 meninas. Nas escolas subvencionadas havia 1.577 alunos. $^{32}$

\footnotetext{
${ }^{28}$ Para o caso de Inhaúma, ver o estudo de Mysayaka, 2011.

${ }^{29}$ Decreto $^{\circ}$. 38, em 9 de maio de 1893. Regula o ensino público do Distrito Federal. Boletim da Intendência Municipal da Capital Federal, 1893.

${ }^{30}$ Segundo o documento, havia 144 professores catedráticos de $1^{\circ}$ grau, 41 catedráticos de $2^{\circ}$ grau, 301 professores adjuntos e 110 adjuntos interinos. AGCRJ, 12.1.31. Relatório do Diretor Geral de Instrução Pública apresentado ao Prefeito Municipal do DF, em 23 de agosto de 1893, fl. 208.

31 AGCRJ, 12.1.32. Ofício do Diretor Geral de Instrução Pública, José Joaquim do Carmo, respondendo à demanda da Legação Americana, encaminhando ao Ministério das Relações Exteriores, em 1894, fl. 41.

${ }^{32}$ AGCRJ, 12.1.31. Relatório do Diretor Geral de Instrução Pública apresentado ao Prefeito Municipal do DF, em 23 de agosto de 1893, fl. 1.
} 
Como pudemos observar, a partir do cruzamento da legislação de ensino com o corpus documental pertencente ao acervo de Instrução Pública da cidade do Rio de Janeiro, as escolas subvencionadas pela municipalidade eram abertas por iniciativa particular de professores, por meio de requerimentos feitos à Diretoria Geral de Instrução Pública, sob o argumento da situação de pobreza dos alunos e alunas. A prática era comum no século XIX e se manteve no século seguinte (PASCHE, 2014). ${ }^{33}$ Pediam-se escolas para meninos e meninas. ${ }^{34}$ Apenas para dar alguns exemplos, Vargem Grande, pertencente ao $11^{\circ}$ distrito, era, à época, uma região rural e pouco habitada. Nem por isso ficou fora dos pedidos de abertura de escola. Em 1895, Rita Alves dos Santos solicitou a abertura de uma escola para meninas na localidade, argumentando que não existia nenhum tipo de escola pública ou particular, "sendo grande parte das meninas completamente analfabetas". ${ }^{35}$ Já em Irajá, 90 distrito, o abaixo-assinado requeria "escola de instrução primária de primeiro grau para o sexo masculino", devido à existência "grande número de crianças em condições de matricula escolar, e todas reconhecidamente pobres". ${ }^{36}$ Em agosto de 1900, a professora Alice Bastos de Mirandella solicitou a manutenção da subvenção da escola em que era professora, na localidade de Magarça, em Guaratiba. A suplicante continuava mantendo a escola com 26 alunos, todos filhos de "pequenos lavradores paupérrimos". ${ }^{37}$ As professoras recebiam auxílio para o aluguel das casas, mobiliário, material escolar e subsídio durante o período escolar. A contar pela presença de requerimentos solicitando a manutenção da escola ou pagamentos a que julgavam ter direito, a incerteza rodeava as escolas subvencionadas. Em fevereiro de 1900, a professora de uma escola primária subvencionada, situada em Inhaúma, solicitou à municipalidade o pagamento dos meses de novembro e dezembro, alegando ter exercido

de acordo com o programa de ensino municipal as funções do seu cargo com uma matricula de 50 alunos, todos gratuitos, e com casa alugada exclusivamente para uso da escola, como de tudo tem sciencia o respectivo Inspector escolar do districto. ${ }^{38}$

Na parte superior da folha, anotou-se: "O pedido pode ser deferido". A probabilidade de terem seus pedidos deferidos possivelmente estimulou muitas professoras a tentarem o subsídio do poder público. Não temos evidências da constituição de redes de solidariedade entre

${ }^{33}$ A primeira lei municipal de ensino republicana, decretada pelo Conselho Municipal e sancionada pela prefeitura em 1893, manteve as escolas subvencionadas, instaladas "nas localidades em que ainda faltarem escolas públicas de $1^{\circ}$ grau, ou em que elas não bastem à grande população escolar", desde que atendam gratuitamente a pelo menos 15 alunos(as) pobres. A iniciativa ficava a cargo do(a) professor(a), por meio de requerimento e atestação do inspetor escolar do distrito, ou do prefeito, quando não houvesse escola disponível. Nesse caso, caberia ao diretor da instrução pública propor pessoa idônea a ser subsidiada para o ensino de crianças pobres da localidade. Decreto $\mathrm{n}^{\circ}$. 38, em 9 de maio de 1893. Regula o ensino público do Distrito Federal. Boletim da Intendência Municipal da Capital Federal, 1893.

${ }^{34}$ Nos códices do Arquivo Geral da Cidade do Rio de Janeiro encontram-se muitos ofícios e abaixo-assinados com pedidos para abertura de escolas públicas e subvenções a escolas particulares. Entre 1891 e 1902, houve solicitações das localidades de Santa Cruz, Vargem Grande, Grumari, Campo Grande, Irajá, Inhaúma, Penha, Caxamorra, Méier, Engenho de Dentro, Encantado, Todos os Santos, Morro da Boa Vista, Piedade, Cachambi, Benfica, São Cristóvão, Ponta do Caju, entre outras. Ver, por exemplo, AGCRJ - Instrução Pública, 12.1.15, 12.1.22, 12.1.24, 12.2.2.

35 AGCRJ - Instrução Pública - 12.1.15 - Requerimentos e ofícios - 1894-1900, fl. 63. Requerimento de $18 / 02 / 1895$.

36 AGCRJ - Instrução Pública - 12.1.15 - Requerimentos e ofícios - 1894-1900, fl. 46. Requerimento de 24/08/1894.

37 AGCRJ - Instrução Pública - 12.1.15 - Requerimentos e ofícios - 1894-1900, fl. 146. Requerimento de 09/08/1900.

38 AGCRJ - Instrução Pública - 12.2.2 - Docentes: requerimentos e ofícios - 1900-1904, sem nº fl. Requerimento de 29/02/1900. 
estas professoras (e nem podemos negá-las, por suposto), mas pelas notícias de aberturas de escolas com subvenção, além dos anúncios de matrículas, nos jornais urbanos e suburbanos, é evidente que as notícias circulavam neste meio. Pela argumentação empregada nos requerimentos, muito parecida - alunos paupérrimos, localidade com grande número de crianças em idade escolar, falta de escolas na região - pressupõe-se que as informações obtidas pelas professoras iam além daquelas noticiadas pela imprensa.

Considerando-se que as áreas suburbanas se concentravam no oitavo distrito escolar em diante $^{39}$, de acordo com a divisão oficial, verifica-se que esta região apresentava um número menor de alunos e alunas matriculados (Tabela II), porém a população também era menor, se comparada à zona urbana da cidade (Tabela I ${ }^{40}$. Havia também nos subúrbios maior incidência de escolas subvencionadas pela municipalidade.

Tabela II - Matrículas nas escolas públicas por distrito escolar (Distrito Federal, $1^{\text {o }}$ semestre de 1893)

\begin{tabular}{|c|c|c|c|}
\hline Distritos & Masculinas & Femininas & Total \\
\hline $1^{\circ}$ & 471 & 401 & 872 \\
\hline $2^{\circ}$. & 417 & 668 & 1.085 \\
\hline $3^{\circ}$. & 352 & 862 & 1.214 \\
\hline $4^{\circ}$. & 1.005 & 760 & 1.765 \\
\hline $5^{\circ}$. & 257 & 585 & 842 \\
\hline $6^{\circ}$. & 671 & 671 & 1.342 \\
\hline $7^{\circ}$. & 364 & 336 & 700 \\
\hline $8^{\circ}$. & 169 & 174 & 343 \\
\hline $9^{\circ}$. & 239 & 154 & 393 \\
\hline $10^{\circ}$. & 271 & 227 & 498 \\
\hline $11^{\circ}$. & 144 & 164 & 308 \\
\hline $12^{\circ}$ & 165 & 95 & 260 \\
\hline Total & 4.525 & 5.097 & 9.622 \\
\hline
\end{tabular}

Fonte: AGCRJ - Instrução Pública - 12.1.31 - Relatórios de instrução pública - 1893-1894, fl. 23.

Nas cidades menores e nas áreas rurais, as matrículas eram mais reduzidas e com menor participação feminina. A despeito da controvérsia gerada pela criação de escolas mistas, estas predominavam no universo das escolas que funcionavam com o subsídio público. Eram escolas de instrução primária, dirigidas a alunos e alunas de menor idade, muito embora, não possamos afirmar que tenham atendido somente crianças. Para as escolas públicas de primeiro grau, a legislação de 1893 prescrevia a sua discriminação em "escolas para meninos" e "escolas para meninas", na faixa dos 7 aos 14 anos, sendo que as escolas femininas, regidas obrigatoriamente por professoras, poderiam receber meninos de até 10 anos. ${ }^{41}$ As regras não foram estendidas às escolas subvencionadas e particulares, deixando para as mesmas certa liberdade de organização

${ }^{39} \mathrm{O}$ decreto $\mathrm{n}^{\mathrm{o}} .38$, de 9 de maio de 1893, dividiu o distrito federal em 12 distritos escolares. Decreto $\mathrm{n}^{\mathbf{o}} .38$, em 9 de maio de 1893. Regula o ensino público do Distrito Federal. Boletim da Intendência Municipal da Capital Federal, 1893, cap. VII , art. 56 e 56, p. 33.

${ }^{40}$ Os números relativos às matrículas e escolas estão reunidos em mapas estatísticos manuscritos, consolidados a partir das informações enviadas pelos professores. Seus organizadores estavam cientes das falhas contidas nos mesmos, pois nem todos atendiam ao ofício emitido pelo Diretor da Instrução Pública, convocando os professores a preencherem o mapa estatístico sem incluir os alunos eliminados até a data prevista para o fornecimento dos dados. Os quadros reunidos na documentação do período ( $1^{\circ}$ sem. 1893) apresentam somente a matrícula, e não a frequência dos alunos e alunas. Já nos ofícios de professores e professoras pedindo o subsídio de suas escolas, era comum o emprego do termo frequência, cientes de que de outra forma não obteriam o benefício desejado. Contudo, não é possível afirmar-se que todos estivessem efetivamente frequentando suas escolas.

${ }^{41}$ Decreto $\mathrm{n}^{\circ}$. 38, em 9 de maio de 1893. Regula o ensino público do Distrito Federal. Boletim da Intendência Municipal da Capital Federal, 1893, cap. II,, art. 7 e 8, p. 26. 
segundo as necessidades e costumes locais. Restrições como a inexistência ou a mudança de escolas de meninos levavam as famílias a recorrem à feminina, como ocorreu em Piedade com a mudança da escola masculina em $1902 .^{42}$

Tabela III - Resumo das Escholas subvencionadas (Distrito Federal, $1^{\circ}$ semestre de 1893).

\begin{tabular}{c|c|c|c|c|c|c}
\hline \multirow{2}{*}{ Districtos } & \multicolumn{3}{|c|}{ Escholas } & \multicolumn{2}{c|}{ Matriculas } & \multirow{2}{*}{ Total } \\
\cline { 2 - 6 } & Mixta & $\begin{array}{c}\text { Sexo } \\
\text { Masc. }\end{array}$ & Sexo Fem. & $\begin{array}{c}\text { Sexo } \\
\text { Masc. }\end{array}$ & Sexo Fem. & \\
\hline \hline $1^{\circ}$. & 3 & & & 41 & 69 & 110 \\
\hline $5^{\circ}$. & & & 3 & & 99 & 99 \\
\hline $7^{\circ}$. & 7 & 1 & 1 & 173 & 270 & 443 \\
\hline $8^{\circ}$. & 4 & & & 91 & 147 & 238 \\
\hline $9^{\circ}$. & 1 & 2 & 1 & 113 & 149 & 262 \\
\hline $10^{\circ}$. & 1 & 3 & & 188 & 18 & 206 \\
\hline $11^{\circ}$. & 2 & 3 & & 165 & 44 & 209 \\
\hline $12^{\circ}$ & 1 & & & 4 & 30 & 34 \\
\hline Total & $\mathbf{1 9}$ & $\mathbf{9}$ & $\mathbf{5}$ & $\mathbf{7 7 5}$ & $\mathbf{8 2 6}$ & $\mathbf{1 . 6 0 1}$ \\
\hline
\end{tabular}

Fonte: AGCRJ - 11.4.23 - Instrução Pública - Estatística de frequência e matrículas (1874-1897).

Em termos de gênero, podemos observar que havia significativa presença feminina nas escolas, com índices maiores na zona urbana, conforme tendência apontada pela historiografia da educação para o século XIX e meados do XX em várias regiões do país.

Na gestão de Pereira Passos (1902-1906), período de grandes reformas urbanas na área central da cidade, a situação da instrução ofertada pelo poder público nos subúrbios não difere substancialmente em relação à primeira década republicana. Não obstante a difusão de diagnósticos otimistas sobre a difusão da rede escolar nas áreas urbanas e suburbanas ${ }^{43}$, mantinha-se a predominância de escolas públicas no primeiro caso e escolas subvencionadas no segundo. Em 1904, existiam, de acordo com dados divulgados pela prefeitura, 273, escolas, sendo 187 escolas primárias regidas por professores do quadro do magistério municipal, 78 escolas elementares e 8 escolas modelos, perfazendo um total de 28.645 alunos. Destas, 68 localizavam-se no subúrbio, sendo 29 primárias e 39 elementares. ${ }^{44}$

Os dados do censo municipal de 1906 indiciam que a despeito das campanhas empreendidas pelos jornais suburbanos para o incremento da instrução nas suas áreas de abrangência e das iniciativas de indivíduos e associações em prol da educação da população, o analfabetismo nos distritos suburbanos se mantinha superior aos urbanos. Em todos os distritos suburbanos homens e mulheres que não sabiam ler se apresentavam em maior número daqueles que sabiam, de acordo com os dados divulgados pelo poder municipal em 1907. A diferença era maior entre as mulheres: $67,7 \%$ das moradoras dos subúrbios não dominavam a leitura, ao contrário das 49,8 \% das moradoras da "cidade". Entre os homens, 58,9\% dos residentes nos subúrbios não sabiam ler em contraposição aos 39,6\% das áreas urbanas. A diferença de gênero também ocorria na área urbana: 60,4\% dos homens e 50,2 \% das mulheres sabiam ler.

A atuação do poder público, concentrada nas áreas urbanas desde o século XIX, teve os seus efeitos. A presença de escolas públicas com professores efetivos, de escolas modelos (herança dos estabelecimentos conhecidos como "escolas do imperador", construídos a partir

\footnotetext{
${ }^{42}$ PROGRESSO SUBURBANO. Instrucção Publica, 6/08/1902, edição 11, p. 3.

${ }^{43}$ A respeito desta discussão, ver o trabalho de Marques, 2015.

${ }^{44}$ Mensagem do Prefeito à Intendência Municipal, de 1904, citada por Marques, 2015. As escolas elementares possuíam apenas duas classes e as primárias ofereceriam os cursos elementar, médio e complementar em quatro classes, de acordo com a legislação educacional de 1897 e 1898. As primeiras formariam o grupo das escolas subvencionadas, predominantes nos subúrbios (MARQUES, 2015).
} 
da década de 1870), da escola normal, essa situada em área central e muito populosa da cidade (Distrito de Santana), e das iniciativas particulares e das associações, parece ter causado impacto no censo do município. Na outra margem, na imensa região, fortemente marcada pela vida rural nas áreas afastadas da linha do trem, a precariedade da atuação da prefeitura deixava suas marcas, reclamadas nos meios de divulgação disponíveis à época. Tal disparidade não passou despercebida pelo poder municipal, o qual determinou a transferência de escolas situadas em regiões bem servidas para outras carentes das mesmas, nos distritos mais distantes. Na mensagem lida pelo Prefeito Francisco Pereira Passos na sessão do Conselho Municipal, de 05 de setembro de 1906, e publicada na íntegra na edição de sábado, do dia 15 de setembro, pelo jornal Correio da Manhã, o público é informado da transferência de 12 escolas das áreas centrais, com frequência que não compensava a sua manutenção, para o "subúrbio rural" (MARQUES, 2015). Na gestão da instrução pública, jogava-se com a troca ou com o subsidio de escolas diante do espetáculo dos números: o aumento da matrícula escolar, exposto no relatório publicado no jornal, frente a um orçamento minguado.

Tabela IV - Total da população por sexo que sabem e não sabem ler - 1906.

\begin{tabular}{|c|c|c|c|c|c|c|c|c|c|c|c|c|c|c|c|}
\hline \multirow{2}{*}{ ÁREAS } & \multicolumn{5}{|c|}{ SABEM LER } & \multicolumn{5}{|c|}{ NÃO SABEM LER } & \multicolumn{5}{|c|}{ TOTAL } \\
\hline & $\mathrm{H}$ & $\%$ & $\mathrm{M}$ & $\%$ & $\mathrm{~T}$ & $\mathrm{H}$ & $\%$ & $\mathrm{M}$ & $\%$ & $\mathrm{~T}$ & $\mathrm{H}$ & $\%$ & $\mathrm{M}$ & $\%$ & $\mathrm{~T}$ \\
\hline Cidade & 214.855 & 60,4 & 133.774 & 50,2 & 348.629 & 140.646 & 39,6 & 132.658 & 49,8 & 273.304 & 355.501 & & 266.432 & & 621.933 \\
\hline Subúrbios & 41.861 & 41,1 & 26.315 & 32,3 & 68.176 & 60.048 & 58,9 & 55.178 & 67,7 & 115.226 & 101.909 & & 81.493 & & 183.402 \\
\hline $\begin{array}{l}\text { Pop. } \\
\text { Terrestre }\end{array}$ & 256.716 & 56,1 & 160.089 & 46,0 & 416.805 & 200.694 & 43,9 & 187.836 & 54,0 & 388.530 & 457.410 & 56,8 & 347.925 & 43,2 & 805.335 \\
\hline $\begin{array}{l}\text { Pop. } \\
\text { Marítima }\end{array}$ & 4.225 & 70,0 & 42 & 64,6 & 4.267 & 1.818 & 30,0 & 23 & 35,4 & 1.841 & 6.043 & 98,9 & 65 & 1,1 & 6.108 \\
\hline $\begin{array}{l}\text { População } \\
\text { total }\end{array}$ & 260.941 & 62,0 & 160.131 & 38,0 & 421.072 & 202.512 & 51,9 & 187.859 & 48,1 & 390.371 & 463.453 & 57,1 & 347.990 & 42,9 & 811.443 \\
\hline
\end{tabular}

Fonte: Adaptado de Marques, 2013, p. 45, e Recenseamento, 1907, p. 109.

Na faixa etária da idade escolar (6 a 15 anos), as taxas de analfabetismo dos "subúrbios" se mantêm bastante baixas em relação aos da "cidade": 65,3\% para os meninos e 68,3\% para as meninas residentes nos distritos suburbanos. Os dados da tabela $\mathrm{V}$ indicam a grande disparidade entre os moradores das zonas urbanas e os das zonas suburbanas no que se refere ao acesso à instrução.

Tabela V - População por sexo, idade e grau de instrução - 1906.

\begin{tabular}{|c|c|c|c|c|c|c|c|c|c|c|c|c|c|c|c|}
\hline \multirow{3}{*}{ ÁREAS } & \multicolumn{15}{|c|}{ FAIXA ETÁRIA DE 06 A 15 ANOS } \\
\hline & \multicolumn{5}{|c|}{ SABEM LER } & \multicolumn{5}{|c|}{ NÃO SABEM LER } & \multicolumn{5}{|c|}{ TOTAL } \\
\hline & $\mathrm{H}$ & $\%$ & $\mathrm{M}$ & $\%$ & $\mathrm{~T}$ & $\mathrm{H}$ & $\%$ & $\mathrm{M}$ & $\%$ & $\mathrm{~T}$ & $\mathrm{H}$ & $\%$ & $\mathrm{M}$ & $\%$ & $\mathrm{~T}$ \\
\hline Cidade & 31.210 & 54,2 & 26.131 & 51,5 & 57.341 & 26.403 & 45,8 & 24.619 & 48,5 & 51.022 & 57.613 & & 50.750 & & 108.363 \\
\hline Subúrbios & 7.797 & 34,7 & 5.882 & 31,7 & 13.679 & 14.673 & 65,3 & 12.679 & 68,3 & 27.352 & 22.470 & & 18.561 & & 41.031 \\
\hline $\begin{array}{l}\text { Pop. } \\
\text { Terrestre }\end{array}$ & 39.007 & 48,7 & 32.013 & 46,2 & 71.020 & 41.076 & 51,3 & 37.298 & 53,8 & 78.374 & 80.083 & 53,6 & 69.311 & 46,4 & 149.394 \\
\hline $\begin{array}{l}\text { Pop. } \\
\text { marítima }\end{array}$ & 15 & 35,7 & 6 & 60,0 & 21 & 27 & 64,3 & 4 & 40,0 & 31 & 42 & 80,8 & 10 & 19,2 & 52 \\
\hline $\begin{array}{l}\text { População } \\
\text { total }\end{array}$ & 39.022 & 54,9 & 32.019 & 45,1 & 71.041 & 41.103 & 54,7 & 37.302 & 47,6 & 78.405 & 80.125 & 53,6 & 69.321 & 46,4 & 149.446 \\
\hline
\end{tabular}

Fonte: Adaptado de Marques, 2013, p. 47, e Recenseamento, 1907, p. 113.

Os altos índices de analfabetismo vão ao encontro à constatação da historiografia de que o êxodo para as áreas suburbanas se deu em grande parte entre a população mais empobrecida da cidade, composta por operários não especializados. Em obra de Lima Barreto, Clara dos Anjos, o subúrbio era representado pela pobreza e pelo descaso do poder público. No "refúgio dos infelizes", a população suburbana realizava peregrinações diárias pelos trens e bondes, 
seguindo os trilhos para o centro da cidade em busca do ganha-pão. Eram “operários, pequenos empregados, militares de todas as patentes, inferiores de milícias prestantes, funcionários públicos e gente que, apesar de honesta, vive de pequenas transações" (BARRETO, 1922, p. 39). O aumento no número de escolas e cursos diversos na região, a partir principalmente da iniciativa de indivíduos e associações, com ou sem o apoio da municipalidade, e a intensa campanha pela civilização e progresso dos subúrbios, empreendida pelos jornais, associações e sociedades dos mais diversos tipos ${ }^{45}$, aparentemente não surtiram o efeito desejado. Isto é, ao menos em termos da resposta do poder pública às demandas da população. É o que pode presumir a partir do testemunho do diretor de Instrução Pública do Distrito Federal, Manoel Bonfim (em dezembro de 1905, como interino, e de abril de 1906 a maio de 1907 como efetivo), sobre a demanda popular pela instrução primária, especialmente dos distritos suburbanos:

O povo já está convencido da necessidade de instruir os filhos; já procura a escola primária, já quer o ensino. Pelo menos é o que se nota neste Distrito. Em qualquer ponto da cidade ou do subúrbio, onde se abra uma escola com um professor trabalhador, logo as salas se enchem. Quer um sintoma expressivo? Os chefes políticos - de qualquer das facções, os que recebem as solicitações diretas das populações, o que mais pedem à diretoria de instrução é escolas; se me fosse possível atende-los, já teria criado mais de 20 escolas nestes três meses, para espalhar por Irajá, Inhaúma, Campo Grande, Realengo... E quando apresentam as solicitações, é sem indicar pessoas: pedem, empenhamse, apenas, para que lhes deem bons professores (O PAIZ, Ed. 07866, 17 de abril de 1906, p. 1 apud MARQUES, 2015, p. 38).

\section{Considerações finais}

Conforme apontam Gouvea e Nicácio (2017, p. 373), as demandas por direitos sociais "envolvem uma dimensão espacial e, no caso da escola, sua localização ou ausência expressa as relações entre Estado e populações no acesso à instrução". No caso do Rio de Janeiro, essa dimensão se encontrava ainda entrelaçada a respostas diferenciadas do Estado às demandas populares por instrução, já que a municipalidade privilegiou a subvenção de escolas particulares para atender à população dos subúrbios, quando nas áreas centrais (a "cidade") predominaram as escolas públicas. Além disso, criou uma clivagem orientada pela territorialidade ao instituir as classes de professores públicos urbanos e de suburbanos em 1897.

Deste modo, a divisão administrativa do município ${ }^{46}$, identificando a cidade com o urbano, e o que antes era rural com o suburbano, teve seus efeitos na criação de novas categorias de professores. O decreto n. 52 de 09 de abril de $1897^{47}$ ampliou, de duas para cinco as classes de professores públicos, criando a de professor primário em escolas urbanas e primário em escolas suburbanas. Pelo artigo $17^{\circ}$ do decreto, professoras e professores urbanos e suburbanos seriam nomeados por concurso, sendo obrigatoriamente diplomados pela Escola Normal. A legislação instituiu um claro limite para a mobilidade das "professoras suburbanas", que "só

\footnotetext{
${ }^{45}$ A respeito destas iniciativas, ver o trabalho de Mendonça, 2011.

46 Optamos por manter aqui o termo município, lembrando que, a partir da promulgação da Constituição de 1891, o Município Neutro foi substituído pelo Distrito Federal, que por sua vez, se tornou um estado. (Constituição da República dos Estados Unidos do Brasil, Art. $2^{\circ}$ ).

Disponível em http://www.planalto.gov.br/ccivil_03/constituicao/constituicao91.htm. Acesso em 10/03/2017.

${ }^{47}$ Decreto $^{\circ}$. 52, em 09 de abril de 1897. Regula o ensino público municipal. Boletim da Intendência Municipal da Capital Federal, 1897, p. 23-50.
} 
poderiam ser transferidos para as escolas urbanas se viessem a merecer gratificação adicional" mediante parecer do Conselho Superior. ${ }^{48}$

Contudo, considerando a grande diversidade do que se designava por subúrbios, distritos formados por áreas rurais, vilas de pescadores e aglomerados urbanos, é impossível precisar o impacto e o crescimento da escolarização, bem como seus limites e contradições, sem a realização de estudos específicos sobre cada distrito da grande região. Esta tarefa prossegue como um dos objetivos centrais de nossa pesquisa em andamento. Mas, o investimento é árduo e depende igualmente de estudos de outros pesquisadores interessados na história da cidade. Fica, então, o convite aos historiadores da educação.

\section{Referências}

BARRETO, Afonso Henriques de Lima. Crônicas escolhidas. São Paulo, Ática, 1995.

BARRETO, Afonso Henriques de Lima. Clara dos Anjos, 1922. Disponível em http://www.dominiopublico.gov.br/download/texto/bn000048.pdf

BARRETO, Lima. Feiras e mafuás. Gazeta de Notícias, ano XLVI ed. 206, ano XLVI, ed. 206, p. 2, 28 de julho de 1921.

BENCHIMOL, Jaime Larry. Pereira Passos: um Haussmann tropical. Rio de Janeiro: Secretaria Municipal de Cultura, Turismo e Esportes, Departamento Geral de Documentação e Informação Cultural, Divisão de Editoração, 1992.

BRAZIL. Ministério do Império. Relatório apresentado à Assembleia Legislativa na $1^{\mathrm{a}}$ sessão da $16^{a}$ legislatura pelo Ministro e Secretario de Estado dos Negocios do Imperio Conselheiro Dr. José Bento da Cunha Figueiredo. Rio de Janeiro: Typografia Nacional, 1877. Disponível em: http://brazil.crl.edu/bsd/bsd/u1742/000001.html

GOUVEA, Maria Cristina Soares; NICÁCIO, Karina. Escolarização e territorialidade na Cidade Republicana: Belo Horizonte (1897-1912). História da Educação, v. 1, n. 51, p. 371390, jan./abr. 2017.

LIMEIRA, Aline de Morais. O comércio da instrução: práticas educativas e publicidade no século XIX. Linguagem, Educação e Sociedade (UFPI), v. 13, p. 84-102, 2008.

LIMEIRA, Aline de Morais. O Comércio da Instrução no século XIX: colégios particulares, propagandas e subvenções públicas. Rio de Janeiro: UERJ, 282fL. Dissertação (Mestrado em Educação). Programa de Pós-Graduação em Educação, Universidade do Estado do Rio de Janeiro, Rio de Janeiro, 2010.

MARQUES, Jucinato de Sequeira. O fio e os rastros da escolarização do Distrito Federal (1890-1906). Rio de Janeiro: UFRJ, 2015, 233f. Tese (Doutorado em Educação). Programa de Pós-Graduação em Educação, Universidade Federal do Rio de Janeiro.

MARQUES, Jucinato de Sequeira. O processo de escolarização do Distrito Federal (18881906). Rio de Janeiro: Universidade Federal do Rio de Janeiro-PPGE, 2013.

\footnotetext{
${ }^{48}$ Esse benefício estava atrelado à média de aprovação do aluno, nos exames finais, dos últimos cinco anos (MARQUES, 2015, p. 169). No parágrafo que o descreve é empregado somente o termo no feminino: "professoras suburbanas".
} 
MARTINEZ, Alessandra Frota. Niterói, RJ: UFF, 241f. Educar e instruir: a instrução popular na Corte imperial. Dissertação (Mestrado em História). Programa de Pós-Graduação em História, Universidade Federal Fluminense, Niterói, 1997.

MENDONÇA, Leandro. Nas margens: experiências de suburbanos com periodismo no Rio de Janeiro, 1880-1920. Niterói, RJ: UFF, 2011, 149f. Dissertação (Mestrado em História Social). Programa de Pós-Graduação em História, Universidade Federal Fluminense.

MIYASAKA, Cristiane Regina. Viver nos subúrbios: a experiência dos trabalhadores de Inhaúma (Rio de Janeiro, 1890-1910). Rio de Janeiro: Secretaria Municipal de Cultura/ Arquivo Geral da Cidade do Rio de Janeiro, 2011.

PASCHE, Aline de Morais Limeira. Entre o trono e o altar: sujeitos, saberes e instituições escolares na capital do Império (1860-1880). Rio de Janeiro: UERJ, 372f. Tese. Doutorado em Educação, Programa de Pós-Graduação em Educação. Rio de Janeiro, Universidade do Estado do Rio de Janeiro, 2014.

RECENSEAMENTO DO RIO DE JANEIRO (Districto Federal). Realisado em 20 de setembro de 1906, Rio de Janeiro, Officina da Estatistica, 1907.

SCHUELER, Alessandra. Trajetórias cruzadas e ação docente em luta por educação: André Rebouças, José do Patrocínio e Manuel Querino. In: FONSECA, Marcus Vinícius; BARROS, Surya Pombo. (orgs.) A História da Educação dos Negros no Brasil. Niterói, EDUFF, 2016, p. 191-216.

SEVCENKO, Nicolau. Literatura como missão: tensões sociais e criação cultural na Primeira República. 2. ed. São Paulo, Companhia das Letras, 2003.

REVEL, Jacques (org.). Jogos de escalas: a experiência da microanálise. Rio de Janeiro: Fundação Getúlio Vargas, 1998.

SILVA, Eduardo. As queixas do povo. Rio de Janeiro, Paz e Terra, 1988.

SILVA, Raphael Frederico Acioli Moreira. Os macaquitos na Bruzindanga. Racismo, folclore e nação em Lima Barreto (1881-1922). In: CHALHOUB, Sidney; NEVES, Margarida de Souza; PEREIRA, Leonardo Affonso de Miranda (orgs.). Histórias em cousas miúdas: capítulos de história social da crônica no Brasil. Campinas, São Paulo, Editora da Unicamp, 2005, p. 159-198. 